\title{
Unusual Suicide Cases of Asphyxiation by Ligature within the Vehicle
}

Dae Yoil Kim¹, SangHan Lee ${ }^{2}$

${ }^{1}$ Scientific Investigation Department, Gyeongbuk Provincial Police Agency, Andong, Korea, ${ }^{2}$ Department of Forensic Medicine, School of Medicine, Kyungpook National University, Daegu, Korea

Received: January 30, 2020

Revised: February 16, 2020

Accepted: February 25, 2020

\section{Correspondence to}

SangHan Lee

Department of Forensic Medicine,

School of Medicine, Kyungpook

National University, 680

Gukchaebosang-ro, Jung-gu, Daegu

41944, Korea

Tel: +82-53-420-4887

Fax: +82-53-422-4712

E-mail: sanghan1@knu.ac.kr
One of the most common methods of suicide is hanging, and suicide by ligature strangulation is quite rare. Vehicles have a confined space, making them an unusual place for committing suicide by hanging or ligature strangulation, because they are more typically the location of suicide by carbon monoxide intoxication by briquette or drug intoxication. Here, we present three cases of unusual suicide by ligature strangulation, discuss the mechanism of asphyxia in each case, and review the literature. In case 1, the victim used a backpack to perform reverse hanging by wrapping the shoulder strap of the backpack around his neck and then tossing the backpack behind the backrest of the driver's seat. In case 2, the victim did not use the internal structures of the vehicle, but pulled down on a ligature wrapped around both his knees and neck. In case 3 , the victim hanged himself using a package line fixed to the roof handle grab of the back passenger seat.

Key Words: Vehicle; Hanging; Strangulation; Backpack; Reverse hanging

\section{Introduction}

Asphyxiation is caused by difficulty in oxygen exchange and utilization by cells [1]. Hanging and ligature strangulation are typical types of asphyxia and have the same mechanism of death. The manner of death in almost all cases of hanging is suicide. Self-strangulation means suicidal strangulation. Strangulation itself is very rare, and the practical determination of the manner of death in strangulation cases is very difficult. Death by hanging is possible in any posture. The principle of how the force is applied to cause death can be classified according to whether the victim wrapped a ligature around the neck and applied their weight to the ligature or whether an external force was applied by someone else, the victim's arm, or other force. Cases of ligature strangulation must have the ligature remaining around the neck of the victim; if the ligature is tied to a low position, self-strangulation may not be easily distinguished from incomplete hanging. Meanwhile, vehicles are easy to move to remote places. Vehicles are often used as a place for suicide because they can remain unobtrusive; however, suicide by hanging or self-strangulation within a vehicle is relatively rare due to the relatively narrow space. The authors report three cases of suicide by hanging and self-strangulation in vehicles and also present a literature review. 


\section{Case Report}

\section{Case 1}

The victim was a 37-year-old man who lived with his wife. The day before his death, while drinking with friends at a restaurant, he had gotten into an argument with his wife on the phone. After finishing the meeting with his friends, he did not return home. The next morning, a friend who had been with him the night before discovered the deceased victim seated in the driver's seat of his vehicle with the shoulder strap of his backpack tied around his neck. The victim was seated in the driver's seat with his head positioned in the space between the driver's and passenger's seats, facing the ceiling of the vehicle. His torso was facing the steering wheel, while his left shoulder was resting on the backrest with his right arm on the center console. The shoulder strap of his backpack was tied around his neck. The shoulder strap had a total length of $50 \mathrm{~cm}$ and width of $2 \mathrm{~cm}$, too short to allow the victim to put his head through the strap without first pulling it out through the friction buckle. Therefore, it was suspected that the victim had pulled the strap completely through the friction buckle, wrapped the strap around his neck, and then reinserted the strap through the friction buckle (Fig. 1). It was also suspected that the victim subsequently tossed the bag (weight, $8.04 \mathrm{~kg}$ ) behind the backrest of the driver's seat, which caused his death.
The autopsy showed that the victim had a slight build with a height of $174 \mathrm{~cm}$ and weight of $48 \mathrm{~kg}$. Severe facial congestion and multiple petechial hemorrhages were found on his face and palpebral conjunctiva. The mark on his neck matched the fiber weave pattern of the backpack shoulder strap, leaving a parallel mark $1.5-2 \mathrm{~cm}$ in width. Internal examination showed diffuse mild congestive hemorrhage in the subcutaneous soft tissue above the strangulation mark. Severe congestion was also found in the base of his tongue. Multiple dots and spotty hemorrhages were observed in the inner larynx, without thyroid cartilage or hyoid bone fracture. No specific pathological findings were noted in his internal solid organs and tissues. Toxicology test results showed a blood ethyl alcohol level of $0.172 \%$. All other toxicology test results were negative. DNA from another person was not detected under the fingernails of both hands. The trace evidence test revealed the same fiber as the backpack shoulder strap on both hands. The victim had no history of treatment for a mental illness, no history of prior suicide attempts, and no financial problems. The victim was under stress for businessrelated payment issues, although it was his usual disposition to anger easily. No suicide note was found at the scene. Inspection of the inside and outside of the vehicle, nearby closed-circuit television (CCTV) footage, credit card use, and phone records did not reveal any evidence or anomaly indicating a suspicion of homicide. The medical examiner determined the cause of death

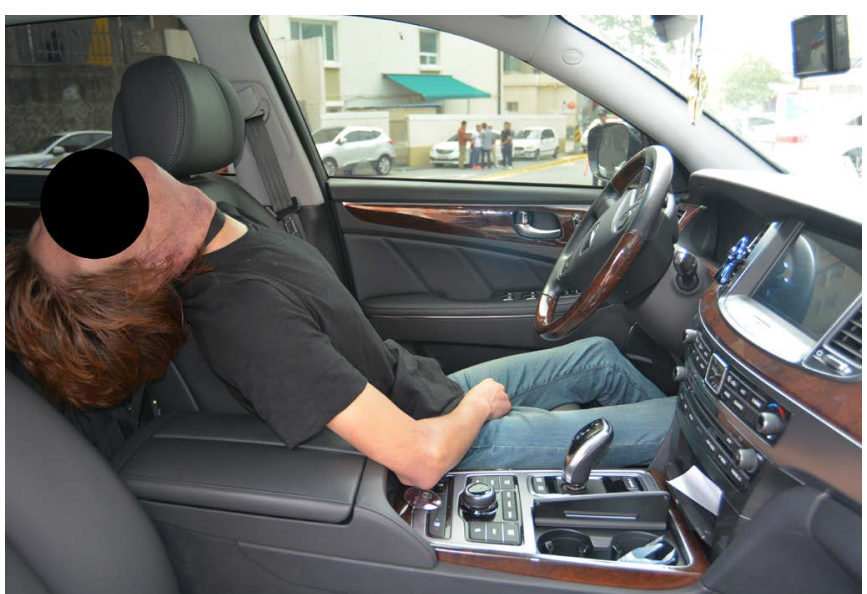

A

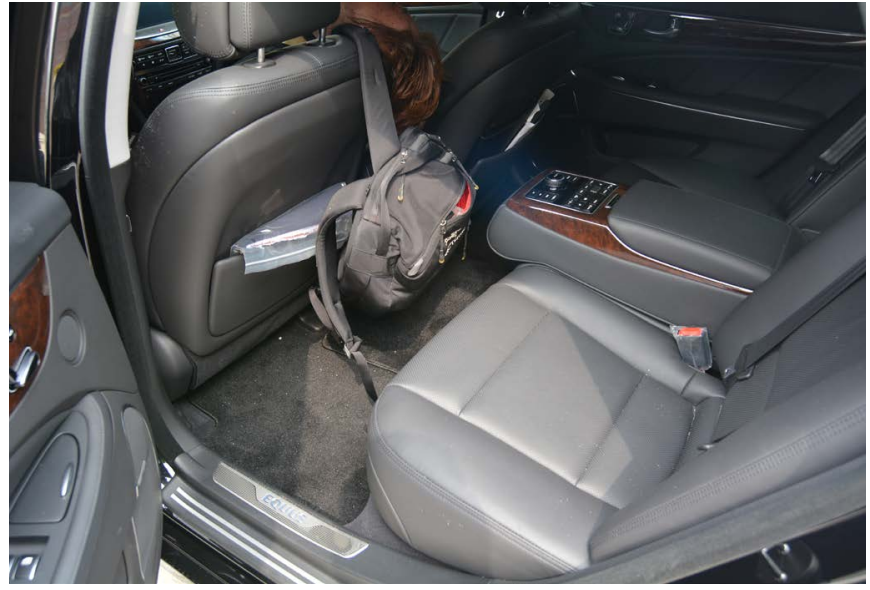

B

Fig. 1. (A) The victim was sitting in the driver's seat with his neck tilted backward. The victim showed severe facial congestion. (B) The backpack was placed behind the backrest of the driver's seat. 
to be suicide by self-strangulation.

\section{Case 2}

The victim was a 53-year-old single man who lived with his elderly parents. He told his parents that he was going out to get some fresh air. The victim was later found dead, sitting in the driver's seat of his father's sport utility vehicle, which was parked in the rest area on the side of the expressway. An Expressway Corporation employee noticed that the vehicle had been parked for a long time and that the driver inside had also remained in the same position. The doors of the vehicle were not locked and the victim was sitting in the driver's seat with his head resting on the horn of the steering wheel. The method used to commit suicide was suspected to have involved wrapping an orange-colored laundry line (plastic rope) around his neck once, tying both ends of the rope to the popliteal area behind each knee, and pulling on the rope (Fig. 2 ). The total length of the rope was approximately $230 \mathrm{~cm}$, and it was approximately $0.5 \mathrm{~cm}$ wide. Dried blood from the victim's nose was found on the horn on the steering wheel and the front part of the driver's seat. External examination revealed congestion and multiple dot hemorrhages on the facial skin and palpebral conjunctiva. The ligature mark ran from $5 \mathrm{~cm}$ directly below the chin to approximately $7 \mathrm{~cm}$ directly below both outer ears, with two lines running across the back of his neck. Besides the evidence of tying the rope behind each knee, there were no other anomalies such as signs of assault or defense wounds indicating a suspicion of homicide. A short memo-type suicide note drafted by the victim was found inside the glove box of the vehicle. Approximately one year earlier, the victim had been diagnosed with schizophrenia and hallucinations at a tertiary hospital, for which he underwent subsequent drug administration and outpatient care. Onsite and other investigations by the police did not reveal any evidence to suggest homicide. An autopsy was not performed.

\section{Case 3}

The victim was a 46-year-old man. He lived with his wife and child and worked at a car rental company. A coworker of the victim became suspicious when he did not show up at home or work for several days; a check of the places where the victim had used the company credit card and nearby public parking lots the victim frequently used revealed a company car in one of the parking lots. The victim was found sitting on the floor behind the passenger seat with his legs extended. He had hanged himself with a nylon rope (package line) tied to the handle located above his head. The doors of the vehicle were not locked. The height of the interior roof handle grab of the back-seat area, where the rope was tied, was approximately $105 \mathrm{~cm}$ from the floor,

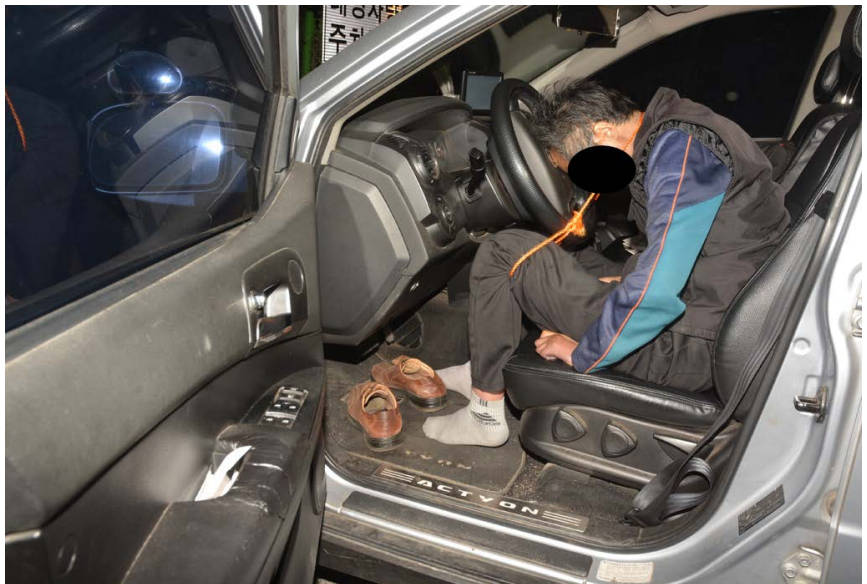

A

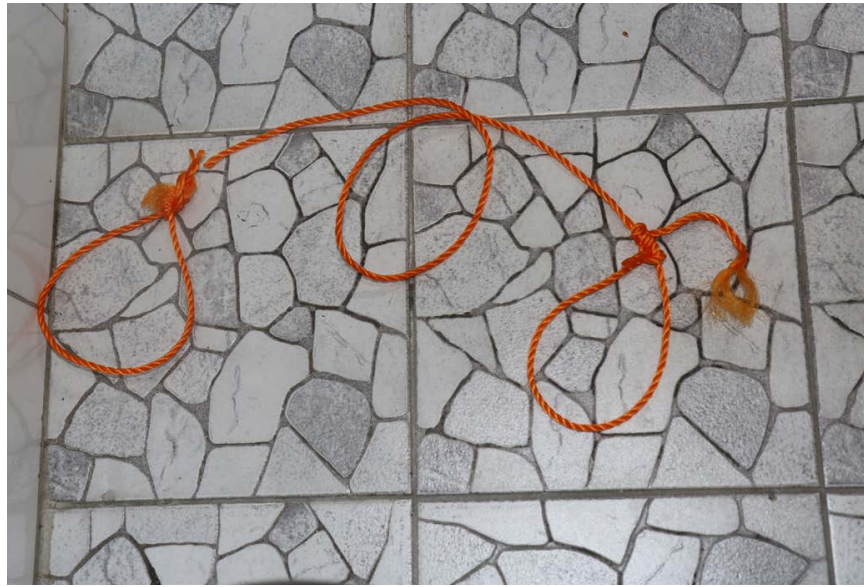

B

Fig. 2. (A) The victim was seated in the driver's seat and his head had moved forward at the driver's handle. (B) The ligature crossed and wrapped once around the neck and was connected with ligatures wrapped separately around his legs. 
while the distance from the knot made in the neck area to the handle was approximately $45.5 \mathrm{~cm}$. The knife used and the remaining bundle of rope were found on the back seat. No suicide note was found on the victim or inside the vehicle. External examination revealed the victim's height to be approximately $175 \mathrm{~cm}$; because putrefaction had set in throughout the body, the formation of putrefaction-associated vesicles, marbling, and putrefaction discoloration were observed. Traces of a natural flow of putrefaction fluid from the mouth and nose in the direction of the body position and gravity were observed. Around his neck, a trace of hanging $0.3-0.7 \mathrm{~cm}$ thick was observed from $6 \mathrm{~cm}$ below the left ear to $4 \mathrm{~cm}$ below the right ear and a knot was made on the back of the head, on the right side (Fig. 3). No other specific injuries such as signs of assault or defense wounds were observed. People familiar with the victim stated that he had struggled with debt and had depressive symptoms. However, he had not been diagnosed or treated at a hospital. The investigation revealed no evidence to suspect homicide. An autopsy was not performed.

\section{Discussion}

Compared to the past, automobiles have become much more accessible. Choosing an automobile as a tool or place for suicide is based on the fact that it provides mobility and a personal and independent space. Hanging is the most common method of suicide in Korea [2]. Vehicles are generally not suitable for hanging or ligature strangulation because they are narrow in space and afford limited movement [3]. However, vehicles are commonly used for suicide via carbon monoxide poisoning using ignition coal in the closed space. Koops and Brinkmann [4] reported only seven cases of ligature strangulation among 15,000 autopsies, while Maxeiner and Bockholdt [5] reported approximately one case of ligature strangulation and 10 cases of homicide annually in Berlin. Thus, the frequency of such cases is very low [6-8]; as a result, very few studies have reported on ligature strangulation, with most being unique case reports [9-14]. Azmak [15] reported that $76 \%$ of 134 hanging cases occurred indoors, primarily inside the victim's home. Only one case occurred inside a vehicle (a bus). Russo et al. [16] reported that $70 \%$ of 260 hanging cases occurred in the victim's home, while $15 \%$ occurred outdoors; only two cases occurred inside a vehicle (trucks belonging to the victims). Tugaleva et al. [17] reported that two of 761 hanging cases occurred inside a vehicle. As shown, cases involving death by hanging or ligature strangulation in a vehicle are very rare [18-22].

While both cases 1 and 2 were cases of ligature strangulation, the principles of how the force was applied to cause death differed. In case 1 , the shoulder

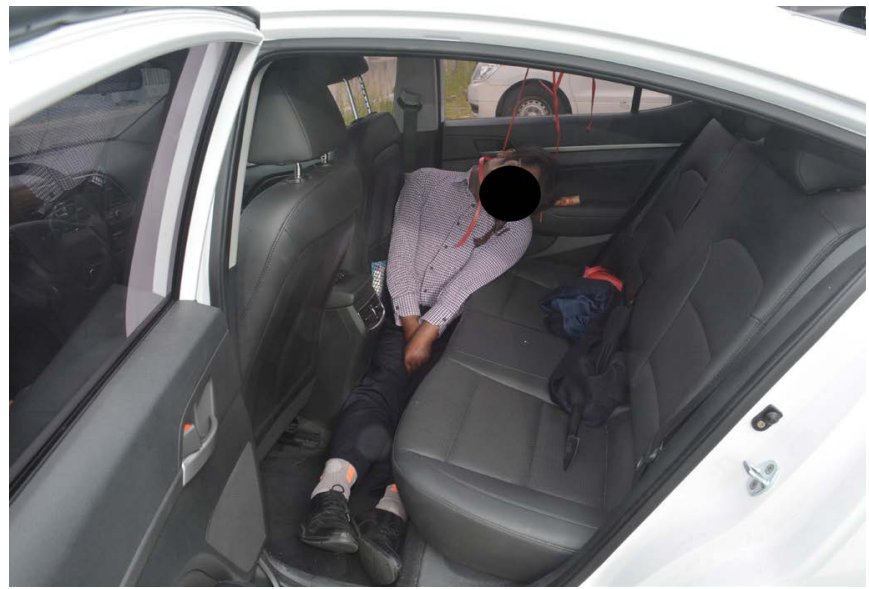

A

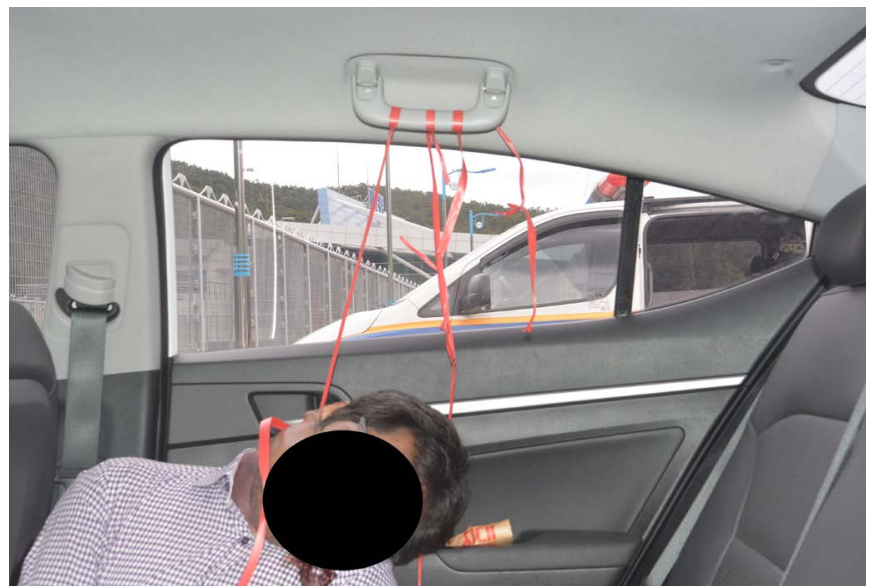

B

Fig. 3. (A) The victim was found sitting on the floor of the back seat with his legs extended. A nylon rope was tied to a handle inside the vehicle, and a knife and bundle of the rope used were found on the back seat. (B) Based on the fact that three suspension points were found on the handle, his two previous attempts had failed. 
strap of a backpack was wrapped around the neck, and the backpack itself was tossed behind the backrest of the driver's seat. Consequently, the weight of the backpack created a pulley action in which the backpack was continuously pulled down by gravity, which caused the strap to be pulled upward toward the point of suspension, resulting in the strangulation of the neck that eventually led to death. In case 2 , the victim did not use structures in the vehicle such as a handle or seat belts; instead, the rope was wrapped once around the neck, and each end of the rope was tied to the left and right knees. The victim applied a strong force and his body weight to pull the rope, which led to death. No other forces other than the victim's strength and body weight were applied, and the cause of death was determined to be ligature strangulation by the rope and neck brace. Several tools, including rope, necktie, belt, cable tie, and blood pressure cuffs, can be used for hanging or ligature strangulation; however, to our knowledge, there has been no reported case in which a backpack was used. In case 3 , the cause of death was incomplete hanging in which the victim was sitting on the floor with his legs extended and the ligature was tied to a handle inside a narrow vehicle. Death by hanging can be achieved regardless of posture. A total of three ligatures were tied to the handle, with signs of one of the ligatures having snapped as it was pulled. The victim had made at least two attempts before succeeding in killing himself.

Cases where death occurs from ligatures being pulled by the weight of an object attached to the ligatures, as in case 1 , are opposite to case 3 , which involved the ligature being fixed to a stationary point with the body weight pulling downward and tightening the ligature by gravitational force. In other words, the force was concentrated on the point of suspension at which the ligature was fixed. Therefore, the neck acted as the point of suspension and the weight of the backpack acted as the body weight in case 1 . The term "reverse hanging" has been proposed to describe this form of ligature strangulation. Among various forms of ligature strangulation, cases of ligature strangulation similar to that reported in case 1 [11] can be more easily understood and explained as reverse hanging.
ORCID: Dae Yoil Kim: https://orcid.org/0000-00029264-3307; SangHan Lee: https://orcid.org/0000-00030390-3494

Conflict of Interest

No potential conflict of interest relevant to this article was reported.

\section{Acknowledgments}

This case report was presented as a poster at 24th Congress of International Academy of Legal Medicine in 2018.

\section{References}

1. DiMaio DJ, DiMaio VJ. Forensic pathology. Boca Raton, FL: CRC Press; 1993. p. 207-51.

2. Kim DY, Lee S, Kim DJ. Review of suicidal electrocution in South Korea from 2008 year to 2018 year. Korean J Leg Med 2019;43:138-43.

3. Kim DY, Lee S. Self-ligature strangulation by utilizing recliner. Korean J Leg Med 2019;43:111-4.

4. Koops E, Brinkmann B. Suicidal strangulation by ligature (author's transl). Z Rechtsmed 1982;88:221-31.

5. Maxeiner $\mathrm{H}$, Bockholdt $\mathrm{B}$. Homicidal and suicidal ligature strangulation: a comparison of the post-mortem findings. Forensic Sci Int 2003;137:60-6.

6. Vanezis P. Pathology of neck injury. London: Butterworth \& Co; 1989. p. 65-71.

7. Saukko P, Knight B. Knight's forensic pathology. 3rd ed. London: Arnold; 2004. p. 379-83.

8. Dolinak D, Matshes EW. Asphyxia. In: Dolinak D, Matshes EW, Lew EO, eds. Forensic pathology: principles and practice. Burlington: Elsevier Academic Press; 2005. p. 201-24.

9. Atilgan M. A case of suicidal ligature strangulation by using a tourniquet method. Am J Forensic Med Pathol 2010;31:85-6.

10. Tzimas I, Bajanowski T, Pollak S, et al. Suicidal ligature strangulation using gymnastics bands. Int J Legal Med 2014;128:313-6.

11. Pramod Kumar GN, Arun M, Manjunatha B, et al. Suicidal strangulation by plastic lock tie. J Forensic Leg Med 2013;20:602.

12. Badiadka KK, Kanchan T, D'Souza DH, et al. An unusual case of self-strangulation by ligature.J Forensic Leg Med 2012;19:434-6.

13. Pramanik P.An unusual method of suicidal ligature strangulation. J Forensic Sci 2016;61:274-6.

14. Lo Pinto S, Tacchella T, Fossati F, et al. Self-strangulation through a sphygmomanometer: an uncommon suicide. J Forensic Sci 2017;62:528-30.

15. Azmak D. Asphyxial deaths: a retrospective study and review of the literature. Am J Forensic Med Pathol 2006;27:134-44. 
16. Russo MC, Verzeletti A, Piras M, et al. Hanging deaths: a retrospective study regarding 260 cases. Am J Forensic Med Pathol 2016;37:141-5.

17. Tugaleva E, Gorassini DR, Shkrum MJ. Retrospective analysis of hanging deaths in Ontario.J Forensic Sci 2016;61:1498-507.

18. Uzun I, Buyuk Y, Gurpinar K. Suicidal hanging: fatalities in Istanbul retrospective analysis of 761 autopsy cases. J Forensic Leg Med 2007;14:406-9.

19. Blanco Pampin JM, Lopez-Abajo Rodriguez BA. Suicidal hanging within an automobile. Am J Forensic Med Pathol 2001;22:367-9.

20. Durso S, Del Vecchio S, Ciallella C. Hanging in an automobile: a report on a unique case history. Am J Forensic Med Pathol 1995;16:352-4.

21. Byard RW, James RA. Unusual motor vehicle suicides. J Clin Forensic Med 2001;8:1-4.

22. Madea B, Schmidt P, Kernbach-Wighton G, et al. Strangulation: suicide at the wheel. Leg Med (Tokyo) 2015;17:512-6. 